\title{
Must the Context Be Considered When Applying Generic Safety Symbols: A Case Study in Flammable Contact Adhesives
}

\author{
J. Paul Frantz, James M. Miller, and Mark R. Lehto
}

\begin{abstract}
Several household fires have occurred in the United States and Canada when flammable contact adhesive vapors were ignited by nearby pilot lights. While the Consumer Product Safety Commission banned the sale of extremely flammable adhesives in the U.S., its Canadian counterparts have focused more attention on product labeling. This field experiment examined the impact of the flame and poison warning symbols prescribed by the Canadian Government for a flammable adhesive. The results suggest that although the generic meanings of these two symbols are well understood, people have difficulty inferring the specific safety precautions most necessary for this particular product, apparently because they do not realize that adhesive vapors, rather than the adhesive itself, pose the fire hazard. Users also tended to overestimate the significance of the toxicity hazard. This incorrect assessment was corrected for a subset of subjects by reading the product specific text provided on the back of the container. Implications for the design and evaluation of safety symbols are provided as are recommendations for modifying several features of the adhesive's label.
\end{abstract}

\section{INTRODUCTION}

Many commonly used safety signage or labeling systems use generic symbols to convey information about both the hazards that may be present when using the product and the precautions that should be taken. The use of symbols has been justified because they can be perceived more quickly than text (Tierney \& King, 1970). Consumers also

J. P. Frantz and J. M. Miller are with the Department of Industrial and Operations Engineering, University of Michigan, Ann Arbor. M. Lehto is an Associate Professor in Industrial Engincering at Purdue University.

Fall 1991/Volume 22/Number 3 often fail to read both written instructions (Wright, Creighton, \& Threlsall, 1982) and warning labels (Lehto \& Miller, 1986). Furthermore, symbols might be useful at the point of purchase by allowing consumers to easily compare the nature and degree of product hazards across brands prior to selecting the product. However, problems can occur if symbols are incorrectly interpreted, especially when people fail to read provided instructions or warning labels.

The comprehension of safety related symbols has been evaluated for both industrial (Collins, Lerner, \& Pierman, 1982) and consumer populations (Easterby \& Hakiel, 1981). In a review of the related literature, Lehto and 
Miller (1986) note that most such studies have evaluated the meaning associated with generic symbols independently of the context within which they are used (e.g., by presenting on a sheet of paper a pictograph that depicts a flame and then asking what it means). This approach can be criticized because the meaning that a symbol is intended to help convey in a particular application may be quite specific. In such situations, the specific meaning must be inferred by applying the generic concept implicit within the symbol to a context specific referent. For example, depending on the context, a pictograph depicting a flame could refer to a solid, liquid, or gas. Quite obviously, the nature of the hazard and associated precautions could vary greatly between each of the three referents in this example.

The critical objective in evaluating applications of generic symbols must therefore be to determine the degree to which the specific intended, rather than the generic, meaning is inferred by the target population when a generic symbol is placed on a product. It is quite conceivable that people who understand the generic concept conveyed by a given symbol may fail to correctly infer its meaning in a particular context because they fail to correctly perceive its referent. To explore this possibility, we chose to examine the impact of two well-recognized, generic symbols on users' understanding of the hazards and necessary safety precautions for flammable contact adhesives. The following discussion first presents a brief history of this product, current labeling strategies, and related research issues. The study and obtained results are then presented.

\section{BACKGROUND}

Contact adhesives are used for installing laminates, wall paneling, and flooring in new or existing homes. Some solvent-based adhesives are considered, by U.S. standards, to be "extremely flammable" due to their low flash point $\left(20^{\circ} \mathrm{F}\right.$ or lower) and rapid evaporation rate. Adhesives are typically dispensed from quart or gallon containers and spread (trowelled) over a large area. As a result, vapors emitted from the adhesive can quickly reach a flammable concentration that can be ignited 148 by a spark or flame. Thus, it is critical that the work area be well ventilated and all sources of ignition eliminated prior to applying a flammable contact adhesive.

The use of such adhesives was associated with numerous household fires and at least 130 injuries (15 of whom subsequently died) in the United States between 1970 and 1976 (Nelson, 1976). The majority of these fires resulted from pilot lights igniting adhesive vapors in the same room or in other rooms throughout the house. As a result of these fires, the U.S. Consumer Product Safety Commission (CPSC) banned the sale of certain extremely flammable contact adhesives to consumers in 1978 (Federal Register, $1977 \mathrm{~b}$ ) after they concluded that changes in product warning labels would not provide adequate protection to the public (Federal Register, 1977a).

\section{Labeling Strategies}

While similar fires occurred in Canada, the sale of flammable adhesives was not banned. Instead, increased attention was given to product labeling as a means of preventing accidental fires. Among other actions, the Canadian government sponsored an industry/government meeting in 1984 to discuss labeling strategies aimed at reducing accidental fires. More recently, the Product Safety Branch proposed an amendment to the Canadian Hazardous Product Act (Canada Gazette, 1989) that would require flammable adhesives to display special warnings on the back panel and lid of the containers. This safety information would supplement the warnings currently required by the Canadian Hazardous Products Regulations.

These latter regulations set forth a labeling system in which objective measures of product characteristics, such as flash point, are associated with symbols denoting the nature of the hazard and a frame surrounding the symbol denoting the degree of the hazard. Figure 1 illustrates the various symbol/frame combinations that could appear on a consumer product. In addition to the symbols, the regulations require that the product display a signal word such as DANGER, a statement of the primary hazard such as FLAMMABLE or VAPOUR HARMFUL, statements of precaution such as Journal of Safety Research 

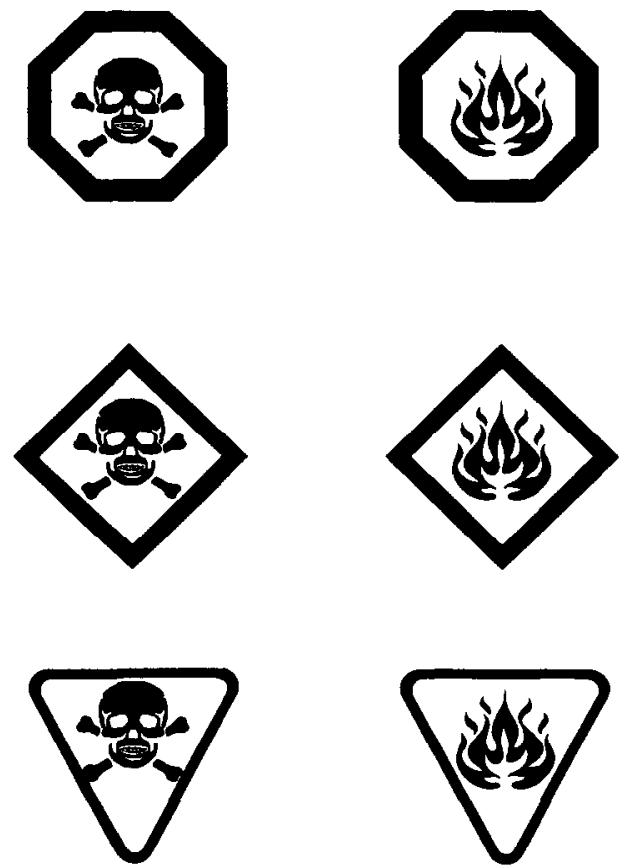

CECC/CCAC No. $190 \quad 15134 \quad$ B-88-03

KEEP AWAY FROM OPEN FLAME OR SPARK, and first aid information.

For contact adhesives, the appropriate symbol, signal word, and statement(s) of primary hazard must appear on the front of the container known as the "principal display panel," but the statements of precaution and first aid information can appear on other panels of the container. The example flammable adhesive label focused on in this study is shown in Figure 2. Note that Figure 2 shows only the English half of the label. The same information is provided in French on the other half of the container.

Products sold in Canada may display additional precautionary information as long as the information does not negate or disclaim any graphic matter required by the regulations. In Figure 2, for example, the manufacturer voluntarily added the following safety information on the back of the label: "CAUTION: All spark producing devices and open flames (furnaces, all pilot lights, spark producing switchFall 1991/Volume 22/Number 3
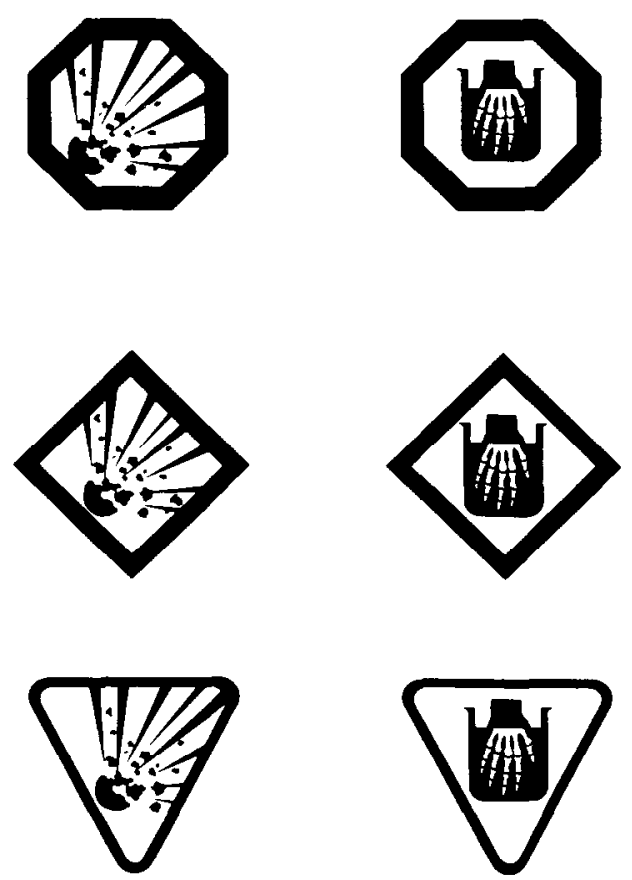

es, motors, etc.) must be eliminated in or near the working area."

\section{Research Issues}

A primary goal of a labeling strategy for flammable contact adhesives is to convey information to the ultimate users of this product regarding the need for a well-ventilated workplace with no sources of ignition. While inhalation of adhesive vapors does present a health concern, the most critical reason for ventilating a work area is to prevent adhesive vapors from reaching a flammable concentration. This being the case, one critical research issue is to determine whether people are able to infer the required information from just the generic symbols appearing on the product. A second issue is to determine whether this understanding is improved when people have the opportunity to read more detailed information on other parts of the label. A third issue 
a. Warning Symbols and Text on Front Panel of Label (Symbol area $=1.875^{\prime \prime} \mathrm{x}$ $3.25 ")$

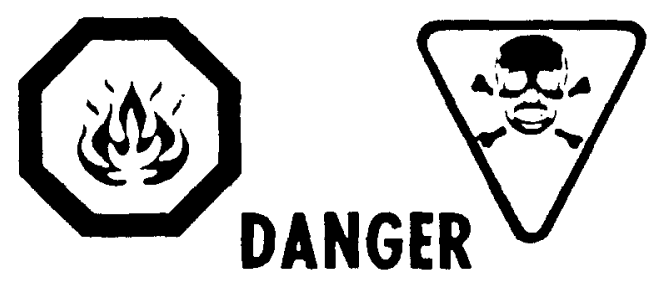

EXTREMELY FLAMMABLE VAPOUR HARMFUL

b. Warning Text on Back Panel of Label (Text area $=.75 " \times 2.125 ")$.

CAUTION: KEEP AWAY FROM OPEN FLAME OR SPARK. USE ONLY UNDER WELL-VENTILATED CONDITIONS. HARMFUL OR FATAL IF SWALLOWED.

CAUTION: All spark producing devices and open flames (Furnaces, all pilot lights, spark-producing switches, motors etc.), must be eliminated, in or near working area.

FIRST AID TREATMENT: Contains a petroleum distillate. If swallowed, do not induce vomiting. Call a physician immediately. If patient is unconscious, give him air.

is to evaluate the influence of information provided in locations other than on the label.

Inference From Symbols Alone. Studying the users' understanding of this adhesive based on their interpretation of the provided symbols alone is critical because, given the typical orientation of the product on the shelf, consumers are likely to view the information on the front of the label before they read the more detailed information on the back. As a result, we hypothesize that initial judgments regarding the risks associated with using the product will probably be formed on the basis of the symbols alone, resulting in at least two potential problems if the symbols are not cor- rectly interpreted. First, this situation lends itself to application of the judgment heuristic known as "adjustment from an anchor" (Tversky \& Kahneman, 1974) in which a person's ultimate judgment about risk or the probability of an event is biased toward their initial assessment of risk (the anchor). Because people typically fail to sufficiently adjust away from the anchor, this heuristic is sometimes referred to as "anchoring and insufficient adjustment." Second, a study by Wright et al. (1982) found that people are less prone to read instructions when they are familiar with a product or use it frequently. It consequently seems likely that users will ignore the product specific text when they are Journal of Safety Research 
confident in the conclusions they develop from viewing the symbols on the front of the label. Such results seem especially likely for those people who have previously used contact adhesives because their understanding of hazards and precautions is likely to be substantially influenced by their prior experience with the product in addition to their interpretation of the symbols.

There is strong evidence that the vast majority of Canadians associate the flame symbol with the concept of flammability. Consider the results of a nationwide survey in Canada regarding the recognition and interpretation of the flame symbol prescribed by the Hazardous Products Regulations. Of those surveyed, $86 \%$ reported that they had seen the flame symbol sometime before and $91 \%$ of the respondents correctly identified the meaning of the symbol (Gallup Canada, 1989).

However, it seems much less likely that people will be able to infer from a flame symbol placed on a contact adhesive's package that vapor concentrations are flammable or that extinguishing pilot lights is a critical precaution. In support of this contention, the results of a U.S. study suggest a similar flame symbol prevalent in the U.S. is widely recognized, but is rather ineffective in conveying the message that vapors can be flammable (Laux, Mayer, \& Thompson, 1989). To further explore this possibility, our study sought to determine the extent to which the flame symbol elicits generic precautions such as "do not smoke" or "keep away from fire" as opposed to eliciting precautions specifically related to vapor flammability such as "turn off pilot lights," which would indicate a more complete understanding of how to use the product safely.

Influence of Text. A potential problem for users who attend to the symbols alone is that they may not accurately and completely understand the hazards and precautions associated with a particular product. The provision of product specific text is one obvious method for remedying any misconceptions that might occur. The possibility of "anchoring and insufficient adjustment," however, indicates that providing additional text will do little to change initial judgments. To evaluate this and the above research issues, we sought to deter- mine the extent to which the two symbols on the front of the label (Figure 2) led to a correct initial assessment of the risks associated with using the adhesive. Our study then addressed the extent to which users modify their initial judgments after they examined the product specific information on the back of the label.

Information on Container Lid. One strategy that has been used to encourage people to read information on the back of the label is to place a message on the container lid. Figure 3 shows the information that has appeared on such a lid in the past. Note that the information on such a "pry-open" type lid will almost always be exposed to the user just prior to dispensing or using the product. Because applicable research has not been conducted, the extent to which providing such information on the lid increases the likelihood that the back of the label is read is unknown. This issue is of particular interest in light of the proposed amendment to the Canadian Hazardous Products Regulations that specifies that similar information appear on flammable adhesive lids. It should be noted that our study was not intended to rigorously test the effectiveness of placing information in this location but, rather, to gain some initial insights into the potential merits of such a labeling strategy.

\section{METHOD}

To address the research issues discussed above, a field experiment was conducted using a verbally administered questionnaire to measure the respondent's understanding of the adhesive's hazards and precautions after viewing certain panels of the container. The interview session was designed to simulate the typical pattern of interaction between users and this adhesive prior to actual use of the product. The introduction to the questionnaire is provided in Table 1 . The complete questionnaire is available upon request.

\section{Respondents and Interview Setting}

The sample of respondents consisted of 100 Canadian residents, 23 who were female and 77 male. The age of the respondents ranged from 19 to 72 years with a 34.6 year average. 
FIGURE 3

INFORMATION APPEARING ON THE LID OF THE CONTAINER IN THE ATTENTION LID CONDITION. THE TEXT WAS GRAY ON A RED BACKGROUND

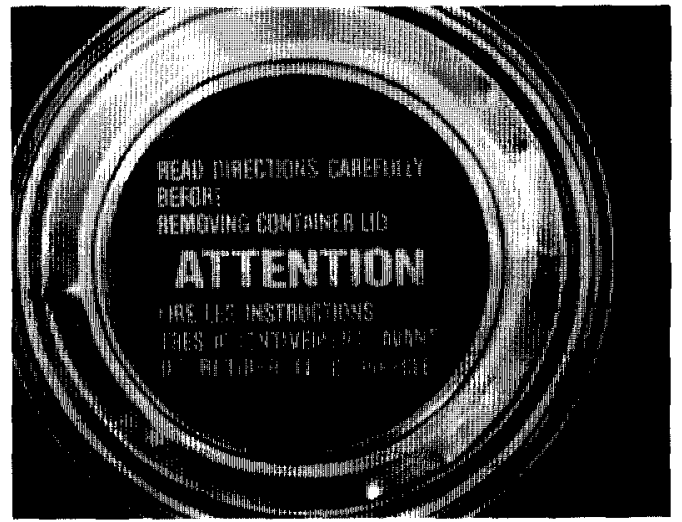

Approximately one half of the sample had attended school beyond the high school level. Seventy-one of the respondents lived in a house, 23 lived in an apartment, and six respondents lived in something other than a house or apartment. Sixty-one respondents had at least one gas appliance in their home. Regarding their prior experience with contact adhesives and related products, 61 of the respondents had used a product similar to the adhesive evaluated here, 60 had seen someone else use a similar product, and 64 of the respondents had personally done some type of remodeling in their home.

Respondents were individually interviewed in popular, well-maintained public parks in Windsor, Ontario frequented by people of varying socioeconomic status. Participants in the study were required to be residents of Canada who had not used this particular product before and who had enough time to unhurriedly complete the interview. The public park setting was chosen over a retail store setting because of the length of the interviews. During pilot studies, customers were interviewed in a hardware store. Data collection in this setting was hampered by the fact that people did not have sufficient time to complete the interview. The public park setting, however, provided a more relaxed atmosphere where people were willing to complete the interview, which typically lasted about 30 minutes.

In selecting potential respondents, we 152 attempted to obtain a sample representative of those who actually purchase and use contact adhesives. Our only indication as to the types of consumers who use (or more precisely, have accidents with) these adhesives came from 35 in-depth accident investigations conducted by the CPSC (Nelson, 1976). These accident investigations found that males were injured three to four times as often as females and that $75 \%$ of the adult users had used a contact adhesive prior to the time of the accidental fire. Also, the vast majority of those involved in the reported accidental fires were between the ages of 21 and 64 . To a reasonable degree, our sample resulted in a similar profile.

\section{Interview Protocol}

To begin the interview, the respondent was informed that we were conducting a study to determine what people thought of the product after seeing certain parts of the can. Each subject was then given a brief description of the adhesive that included its typical uses. Next, the respondent was given a one liter can of adhesive with the back of the label covered by a black cloth and asked to examine the can as if preparing to use the adhesive to attach shower board to the walls around a bathtub. After such examination, the can was removed from sight and the respondent was asked the first set of questions. Responses to the questions were handwritten by the interviewer.

The back of the can was then uncovered and the respondent was asked to read the information on the back of the can just as if preparing to use the adhesive. When the respondent indicated that he/she was ready to use the adhesive, the can was again removed from sight and a second set of questions was administered. Many of the questions were the same as those in the first set. Finally, background information was collected from the respondent and each was given five dollars for participating in the study.

\section{Lid Information Conditions}

To assess the impact of the information provided on the lid of the can, one half of the respondents were given a can with a plain lid while the other half were given a can with a

Journal of Safety Research 
We're doing a study to find out what people think about this product atter they have seen certain parts of this can. I'm not selling anything - I would just like you to look of this can and then l'll ask you some questions. It takes about fifteen minutes and I will be happy to give you five dolkars for helping us with our study. (Hold can in front of respondent)

\begin{abstract}
This producl is a walt punel udhesive. It is generally used to attach decorctive or woterproof paneling to a new or existing wall. You might use this product if, for example, you were remodeling your bathroom and wanted to put up a new material over an existing wall. In your bathroom, this adhesive could be used to glue sheets of shower board, like this piece, to the wall around your bathtub. (Show respondent the piece of shower baard)
\end{abstract}

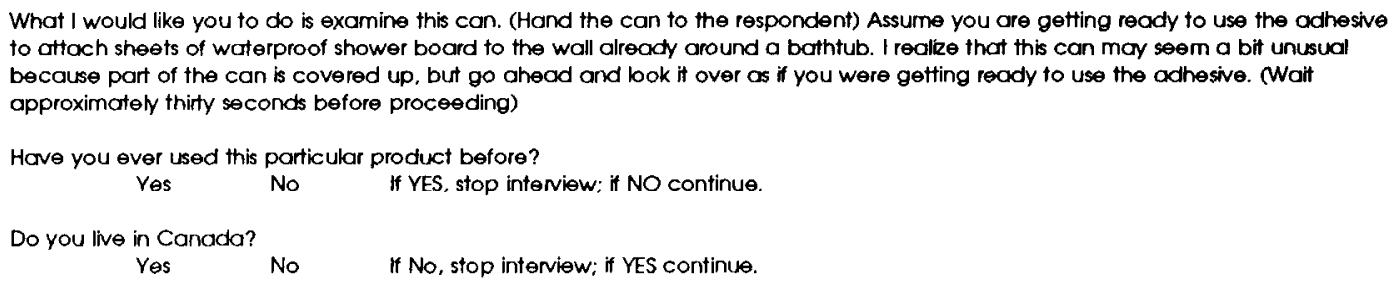

First, I want you to concentrate on these two symbols (point to symbols on the can). So that you can easily study them, here is an exact copy of them. (Give response booklet to respondent and remove can from sight of respondent)

1. Consider these two symbols. What precautions woukd you take if you were using this product in your home?

lid that displayed the information shown in Figure 3. The questions asked of the respondents remained the same for both conditions and at no time were the respondents specifically asked to examine the lid.

\section{RESULTS}

By conducting the structured interviews, a substantial set of data was obtained documenting the information users inferred from the symbols alone regarding their perception of product specific hazards, the relative significance they attached to them, and their selfreports of related precautions. The incremental effect of warning text on the above factors was also documented. Furthermore, specific results were obtained regarding user understanding of vapor flammability and the influence of providing additional information on the lid of the containcr. Thesc results follow.

\section{Initial Impact of Warning Symbols Alone}

After examining the front of the label, respondents were shown only the two symbol/frame graphics shown in Figure 2. They were then asked, "What precautions would you take if you were using this product in Fall 1991/Volume 22/Number 3 your home?" Table 2 displays the precautions reported by respondents along with the frequency of each response.

About one third of the respondents mentioned that they would take precautions either against breathing adhesive vapors or getting the adhesive on their body. This is an interesting result considering that precautions such as wearing protective clothing or using some type of air filtration device are not necessary when using this product. Presumably, it was the poison symbol that prompted these respondents to think of these types of health precautions that may be important for other products bearing this symbol.

With respect to the flame symbol, only 4 respondents out of the 100 participants specifically mentioned that extinguishing pilot lights was a precaution that they would take. For the other respondents who mentioned a general precaution such as "keep away from open flame," it was unclear whether they considered a pilot light several feet away to be an "open flame" type hazard. In addition, it was unclear whether users understood what should be kept from an open flame, the adhesive itself or the vapors emitted by the adhesive.

In another group of questions, respondents were asked how much they would be willing to pay for each of two safer adhesive formulae. They were told that the first new formula 
no longer needed the flame symbol and that the second new formula no longer needed the poison symbol. Respondents were then asked the following: "Assume you are willing to pay $\$ 5$ for this can of adhesive, how much would you be willing to pay for the new formula that does not have this symbol?" (either flame or poison symbol). Respondents reported that they would be willing to pay an average of $\$ 6.42$ for the nonflammable formula and $\$ 7.08$ for the nonpoisonous formula. Both of these prices were significantly higher than the base price of $\$ 5(p<0.001$ for both formulae). The 66 cents difference between the two prices was also significant $[t(99)=3.76, p<0.001]$.

This latter result can be interpreted to mean that the toxicity of the product was perceived by many of the subjects to be a more serious safety concern than the flammability. This issue was examined further with two questions regarding the relative importance of flammability versus toxicity precautions. In the first question, respondents were asked to rank order the following precautions according to their importance to product safety: (a) turn off pilot lights in or near the work area; (b) remove spark producing tools from the work area; (c) wear an air mask; (d) wear protective gloves; and (e) wear glasses or safety goggles. Two of these precautions, "a" and "b," serve to prevent ignition of vapors and, in reality, are necessary. The other three precautions serve to protect one's health while using a product but are not necessary for this particular adhesive.

Table 3 illustrates that subjects, on the average, ranked the fire precautions as being more important than the health precautions. While these results may seem to contradict the earlier findings, note that this was the first time respondents were provided with a list of specific precautions as opposed to having to generate them. Thus, while turning off pilot lights did not occur to most people after seeing only the front of the label, once they were presented with or reminded of this precaution, they apparently had some appreciation for its importance. Also, as mentioned before, the three health precautions are not necessary or prescribed for this product. As a result, one would expect a clear separation in the ranking of these two groups of precautions. That is, if the two fire related precautions were ranked one and two then their combined average ranking should be 1.5 ; similarly, the combined average ranking for the health precautions should be four. Table 3 shows this is clearly

TABLE 2

CONSIDER THESE TWO SYMBOLS. WHAT PRECAUTIONS WOULD YOU TAKE IF YOU WERE USING THIS PRODUCT IN YOUR HOME?

\begin{tabular}{|c|c|}
\hline $\begin{array}{l}\text { Response } \\
\text { Keөp away from/out of reach of children }\end{array}$ & $\begin{array}{l}\text { No. of Respondents } \\
(N=100) \\
65\end{array}$ \\
\hline Keep away from open flarne. heat or sparks & 57 \\
\hline Do not smoke while using adhesive & 45 \\
\hline Ventilate the area/Open windows & 35 \\
\hline Avoid breathing vapors/Wear an air or face mask & 31 \\
\hline Keep off of skin/Wear gloves or protective clothing & 30 \\
\hline Store in a cool place/ke日p can oway from sources of heat & 23 \\
\hline Do not ent, swallow, or ingest & 17 \\
\hline Keep out of eyes/Wear glasses or goggles & 12 \\
\hline Keөp matches or lighters away from adhesive & 9 \\
\hline Close can tightly after use & 7 \\
\hline Do not use adhesive near pilot lights/Turn off pilot lights & 4 \\
\hline Know antidotes or first aid in case of emergency & 3 \\
\hline Keөp fire extinguisher nearby & 3 \\
\hline Other & 19 \\
\hline
\end{tabular}


not the case. The implication is that a significant number of respondents, after seeing only the symbols on front of the label, ranked the less important health precautions as being more important than the critical fire precautions. In fact, looking at the raw data, we found that only 63 of the 100 respondents ranked "turn off pilots in or near the work area" as first or second most important and only 56 ranked "remove spark producing tools from the work area" as first or second most important.

This same type of result was found when respondents were asked to rate the likelihood that they would take various precautions after they had seen just the front of the label. Table 4 shows the average rating for each of the precautions presented to the respondents, both before and after seeing the text on the back of the label. Consistent with the results of the ranking task, the average rating was higher for the truly important precautions ("a" through "e" in Table 4). Note also that ratings for the unnecessary precautions were still quite high. This suggests, again, that many users had difficulty discriminating between necessary and unnecessary precautions after seeing only the symbols on the front of the label.

Interestingly, the precaution with the lowest average rating was "turn off the house's main gas valve." Several respondents remarked during the interview that this precaution was outrageous while others expressed concern that taking this prccaution may actually be more dangerous than using the product. Still others said they did not know how to turn off the house's main gas and that only the gas company should do this. These responses are note- worthy in light of the fact that this statement appears on the lid of a different type of adhesive currently sold to consumers in the U.S.

\section{Impact of Warning Text}

After responding to the questions about the front of the label (the symbols alone), respondents were asked to read the back of the label as if they were preparing to use the adhesive. When they indicated that they had completed their examination of the back of the label and said that they were ready to use the product, the can was removed from sight and they were again asked how much they would be willing to pay for each of the two safer formulae. After being exposed to the back of the label, the average price that respondents were willing to pay for the nonflammable formula increased 94 cents from $\$ 6.42$ to $\$ 7.36$. This increase was significant $[t(99)=-3.92, p<0.01]$. For the nonpoisonous formula, the average price that respondents were willing to pay for the nonpoisonous formula showed an increase of 58 cents from $\$ 7.08$ to $\$ 7.66$, which was also significant $[t(99)=-2.84, p<0.01]$. Recall that, prior to seeing the back of the label, the average price of the nonpoisonous formula was significantly more than that for the nonflammable formula. After being exposed to the back of the label, the average price for the nonpoisonous formula was still greater, but only by 30 cents, which was found to be insignificant $[t(99)=-1.64, p>0.10]$.

After reading the back of the label, subjects were again asked to rate the likelihood that they would engage in various precautionary

TABLE 3

CONSIDER THE FOLLOWING STATEMENTS. FOR THIS PRODUCT, WHICH ONE OF THE FOLLOWING STATEMENTS IS MOST IMPORTANT IN TERMS OF USING THE PRODUCT SAFELY? OF THE FOUR REMAINING STATEMENTS, WHICH ONE IS MOST IMPORTANT IN TERMS OF USING THE PRODUCT SAFELY? ETC.

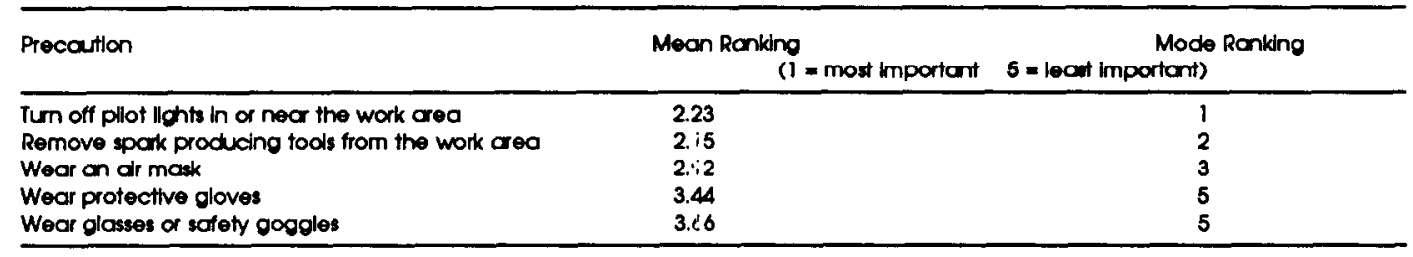


activities. Table 4 shows the average rating for each of the precautions both before and after seeing the back of the label. Paired $t$-tests were conducted to determine if ratings for each precaution changed significantly after respondents read the back of the label. Precautions whose ratings increased significantly are denoted by a single or double asterisk. Note that the mean rating did not decrease for any of the precautions.

After reading the back of the label, respondents were again asked to rank five precautions according to their importance to product safety (see Table 3 for list of precautions). Recall that the two fire precautions are actually important for this product while the three health precautions are not necessary. For the precaution "tum off pilot lights," before reading the back of the label, 63 respondents ranked this as either first or second most important. Afterwards, 78 respondents ranked the precaution as either first or second most important. This change was found to be statistically significant $(p<.05)$ using the chisquare test. For "remove spark producing tools from the work area," before reading the back of the label, 56 respondents ranked this as either first or second most important. Afterwards, 63 respondents ranked the precaution as either first or second most important. This latter effect was not statistically sig- nificant. Nonetheless, these results, in combination with those mentioned above, suggest that reading the back of the label is likely to influence the user's safety knowledge in a positive manner but the extent of such influence is less than one might expect.

\section{Knowledge of Vapor Flammability}

After seeing the front of the label, respondents were asked: "Why might you ventilate the work area?" Table 5 shows that 91 respondents said they would ventilate because the vapors from the adhesive could have some harmful impact on their health, but only 27 respondents mentioned the flammability of the vapors as a reason to ventilate the work area. After examining the back of the label, respondents were asked if there were any other reasons to ventilate the work area besides those previously mentioned. The result of this question was that 10 more respondents reported that vapor flammability was a reason to ventilate the work area. Thus, even after being exposed to the entire label, only about a third of the respondents (a total of 37) reported that vapor flammability was a reason to ventilate the work area. This finding also indicates that the back of the label influenced the respondents in a positive manner but less than one might expect.

TABLE 4

REPORTED LIKELIHOOD TO TAKE PRECAUTIONS BEFORE AND AFTER SEEING THE BACK OF THE LABEL BASED UPON THE FOLLOWING SCALE:

1, I definitely would not do this; 2, I almost certainly would not do this; 3 , I probably would not do this; 4, I might do this; 5 , I probably would do this; 6,1 almost certainly would do this; 7 , I definitely would do this.

\begin{tabular}{|c|c|c|}
\hline Precoution & $\begin{array}{l}\text { Before Seoing } \\
\text { Back of Label } \\
\text { Mean Rating }\end{array}$ & $\begin{array}{l}\text { After Seeing } \\
\text { Back of Label } \\
\text { Mean Rating }\end{array}$ \\
\hline $\begin{array}{l}\text { a. Keep awoy from open flame or spark } \\
\text { b. Read drections before removing the lid } \\
\text { c. Ventilate the work area } \\
\text { d. Remove spark producing devices from the work area } \\
\text { e. Tum off pllot llghts in or near the work area } \\
\text { f. Store in a cool place } \\
\text { g. Wear an air mask } \\
\text { h. Wea eyeglasses or sofety gogdes } \\
\text { l. Wear protectlve gloves } \\
\text { f. Tum off the house's main gas valve }\end{array}$ & 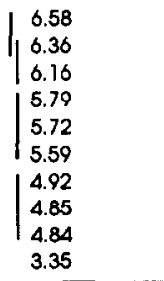 & \begin{tabular}{|l}
6.65 \\
$6.49 \cdots$ \\
$6.29^{* \cdots}$ \\
$6.17^{* *}$ \\
5.61 \\
$5.40^{*}$ \\
5.06 \\
5.11 \\
$4.24^{*}$
\end{tabular} \\
\hline
\end{tabular}

Note: Vertical lines indcote rotings not significontly different from one onother $(p \geq, 10)$.

- Indicctes a significant increase in the mean roting ofter seeing the back of the label $(p<.10)$.

-. Indcates a signiflcant increase in the mean rating after seeing the back of the label (p $\leq .005)$. 


\section{Impact of Information on Lid of Container}

Recall that half of the respondents were given a can with a plain lid and the other half were given a can whose lid displayed the information shown in Figure 3. When respondents from both groups were asked, "how likely are you to read directions before removing the lid," there was no significant difference between the plain lid condition and the ATTENTION lid condition in terms of the reported likelihood to do this (Mann-Whitney $\mathrm{U}$ test, $\left.n_{1}=n_{2}=50, z=-.349, p>.10\right)$. This result suggests that providing the instructions on the lid had little impact on the reported likelihood that instructions on the back of the label would be read before opening the containcr. Note, however, that respondents reported that they were very likely to read the instructions before using the product regardless of the lid condition. Table 4 illustrates that the average likelihood to read directions was second only to "keep away from open flame or spark."

Just prior to examining the back of the label, respondents were asked: "At this point, do you feel that you know enough about this adhesive product to use it or would you want more information about the adhesive before using it?" Eighty percent of the respondents exposed to the plain lid and $88 \%$ of the respondents exposed to the ATTENTION lid said that they would want more information before using the product. The chi-square analysis of these data show this difference to be statistically insignificant $\left[\chi^{2}=1.19, p>0.10\right]$.

With regard to recall of the information provided on the lid, $82 \%$ of the respondents in the ATTENTION lid condition recalled noticing something on the lid but only $28 \%$ recalled that the lid instructed them to read the directions before removing the lid. It should be noted that subjects were never specifically instructed to look at or read information on the lid and respondents did not actually open the container. Thus, we cannot predict what effect actually removing the lid might have on the attention to and compliance with information on the lid. These results do, however, indicate the need for further research regarding the effectiveness of lid information prior to adopting the proposed amendment to the Hazardous Products Regulations.

\section{DISCUSSION}

Regarding the impact of warning symbols on the front of the label, the results of this experiment indicate that, although the flame and poison symbols are recognized by nearly all Canadian users, such symbols do not necessarily elicit safety precautions appropriate for this adhesive proauct. More specifically, although the flame symbol conveys a general message about adhesive flammability to nearly everyone, many users are not able to infer the more specific concept of vapor flammability. Consequently, the provision of a flame symbol on the front of the label is unlikely to prompt users to look for and turn off pilot lights.

Our findings also suggest that users who consider only the symbols on the front of the label are unlikely to correctly judge the relative importance of the poison hazard in relation to the fire hazard. This incorrect assessment of risk may occur because specific acci-

TABLE 5

WHY MIGHT YOU VENTILATE THE WORK AREA (BEFORE EXAMING BACK OF LABEL)? WHY MIGHT YOU VENTILATE THE WORK AREA (BEFORE EXAMINING BACK OF LABEL)?

$\begin{array}{lr}\text { Response } & \text { No. of Resp } \\ \text { (N }=\end{array}$


dent scenarios corresponding to the poison symbol are more easily recalled or imagined by users than those corresponding to the flame symbol. Ingestion, absorption, and inhalation of the adhesive, especially by children, are specific accident scenarios that quickly came to mind for many respondents. However, if a person does not recognize that adhesive vapors are flammable, it is likely to be difficult for them to envision how a serious fire could occur when using the product. Hence, it is not surprising that extinguishing smoking materials was the only specific fire precaution mentioned by more than a handful of respondents. And in many of these cases, the respondent thought that the burning cigarette would have to fall onto the adhesive itself to start a fire.

The assessment of hazardousness based on the ease with which an accident scenario is imagined or recalled would be consistent with the availability heuristic described by Tversky and Kahneman (1974). In their article on the heuristics and biases of human judgment under uncertainty, they state:

There are situations in which people assess the frequency of a class or the probability of an event by the ease with which instances or occurrences can be brought to mind. For example, one may assess the risk of heart attack among middle-aged people by recalling such occurrences among one's acquaintances. Similarly, one may evaluate the probability that a given business adventure will fail by imagining various difficulties it could encounter. This judgment heuristic is called availability.

Unfortunately, the results from our present study indicate that the most frequently documented accident scenario, pilot light ignition of vapors, is not available to many users if they only attend to the symbols on the front of the label.

Several respondents who had previously used a nonflammable type of contact adhesive had difficulty believing that the vapor flammability was the primary hazard for this product. In a discussion held after one interview session, the respondent stated that he had extensive experience with adhesives that were not flammable and that he always wore some type of air filter to prevent inhalation of fumes (in the nonflammable adhesives these are most likely $1,1,1$ trichloroethane vapors). Because of his prior experience and familiarity with the nonflammable adhesive, the respondent said that he would wear some type of respiratory protection even if he used the flammable adhesive; however, he also said that he would not extinguish pilot lights or instruct others to extinguish cigarettes because he knew that adhesive vapors were harmful and not flammable. Such a misunderstanding of the flammable adhesive illustrates the need for manufacturers and government regulators to consider how the use of one product may negatively impact the use of another product that appears to be similar but, in reality, has critically different hazard characteristics.

Regarding the impact of the text provided on the back of the label, respondents generally showed an elevated concern for safety after reading this portion of the label. They were willing to pay more money for both of the safer formulae and their assessment of the flammability hazards relative to the toxicity hazards was corrected somewhat from their initial judgment based on the front of the label only. Perhaps the most important function of the warning text on the back of the label was to alert users to specific sources of ignition and precautions that were not prompted by the flame and poison symbols.

As to respondents' knowledge of vapor flammability, the vast majority of respondents indicated that ventilation was important because inhaling the fumes would be harmful to one's health. The prevalence of this response could be due to the Canadian Hazardous Products Regulations' primary hazard statement, VAPOUR HARMFUL, which is displayed beneath the poison symbol. A number of respondents seemed insulted when asked why they might ventilate the work area. They were quick to point out that the label plainly stated that the vapors were harmful and should be exhausted to prevent excessive inhalation.

Most respondents did not understand that the vapors emitted by the adhesive could be ignited. Less than $40 \%$ of the respondents reported that vapor flammability was a reason to ventilate the work area even after seeing the specific information on the back of the label. The inference to be drawn is that, for this product, the government required statement "Use only under well ventilated conditions" does not 
clearly convey the message that vapors are tlammable even when it follows the statement "Keep away from open flame or spark." The extent to which the poison symbol and words VAPOUR HARMFUL on the front of the label influence the interpretation of "Use only under well ventilated conditions" is unknown. However, the information on the front of the label certainly provides a context for misinterpreting the reason to ventilate the work area.

An additional finding regarding user perceptions of vapor flammability was that a handful of respondents drew an incorrect distinction between the adhesive and gasoline. In thinking about how a fire might occur, several respondents stated that the adhesive was not like gasoline because gasoline vapors could be ignited whereas the adhesive vapors could not. This finding is noteworthy because it indicates that, although a person realizes that some vapors are flammable, they may not consider the adhesive's vapors to be flammable. Identifying those features of a product which suggest that its vapors might be flammable is an important research question applicable to a host of consumer and industrial products with flammable vapors for which this same confusion may exist.

\section{IMPLICATIONS}

This study has several strong implications pertaining to the design and evaluation of warning symbols. To begin with, recall that virtually all of the respondents recognized the flame symbol, but many did not infer the specific nature of the hazard or specific precautions needed for this product. A potential problem with general recognition without adequate inference of specific meaning is that mere recognition of the flame symbol can result in a false sense of security when using the product. That is, if the user sees the flame symbol and concludes that it is the adhesive rather than the vapors that are flammable, then they probably will not recognize the hazards associated with vapor flammability. Most seriously, in this situation they may not sense a need for obtaining more information by reading the product specific text on the back of the label. It seems likely that these findings can be extended to other symbols and product specific contexts. Consequently, the merits of using a warning symbol should be carefully considered in the context of a particular product.

We further conclude that the presence of one symbol on a product can influence the interpretation of other symbols as wcll as the warning text presented on the label. Thus, in many cases, the evaluation of symbol interpretation and effectiveness will need to be conducted in the context of the entire label rather than testing the symbol in isolation.

\section{RECOMMENDATIONS}

The results of this study provide a basis for several modifications to labels affixed to adhesives sold in Canada. In the remainder of the paper, we present four recommendations aimed at increasing the awareness of and appreciation for the hazards and precautions associated with flammable adhesives. It should be noted that, although they are well founded, empirical testing is needed to determine the actual effect of implementing one or more of the recommendations.

The first recommendation is to make the flame symbol substantially larger than the skull and crossbones. The difference in size might provide the user with a more accurate understanding of the relative severity of the two hazards. Recall that the hazard frames surrounding the symbols are meant to convey the severity of a particular hazard, not the relative severity between different hazards.

A second recommendation concerns the statements of primary hazard (i.e., EXTREMELY FLAMMABLE and VAPOUR HARMFUL). Given that the adhesive's most prominent and least understood hazard is vapor flammability, we recommend that a more specific primary hazard statement such as FLAMMABLE VAPOURS be used in place of the generic EXTREMELY FLAMMABLE phrase currently prescribed by the Hazardous Products Regulations. The well-recognized, generic flame symbol accompanied by the product specific statement, FLAMMABLE VAPOURS, is likely to instantiate a more accurate representation of the adhesive's hazards and increase the likelihood that users would take appropriate precautions. However, 
for this modification to be effective, users must process both the symbol and text. With the current level of redundancy between the symbols and text on hazardous consumer products (e.g., the words Extremely Flammable printed beneath a flame symbol), some users may routinely truncate their search for information immediately after encountering a familiar symbol such as the flame symbol or the skull and crossbones. Without data on user processing of primary hazard statements, it is difficult to predict the impact of this recommendation.

The third recommendation is to include warnings and safety precautions within stepby-step directions for using the product. Currently, most adhesive labels separate safety-related information from directions for use. Our recommendation is based on the assertion that most people purchase and use products to perform tasks and accomplish goals, which typically do not include learning about the product's composition or its hazard characteristics. It follows, then, that a user's information search and subsequent text processing will be driven by their desire to actually use the product. This implies that users will search for and read information that appears to be relevant to the use of the product, namely, directions for use. Thus, warnings and safety precautions are more likely to be read if they are included in procedural information, which appears to be directly related to task accomplishment. Research by Fricdmann (1988) involving a wood cleaning product provides support for this argument.

A final recommendation is to provide more information specifically addressing vapor flammability and accident scenarios common to this product. Since this is difficult to accomplish given the limited amount of space on the container, we recommend attaching or enclosing a folded leaflet that verbally and graphically describes the hazards and precautions associated with the adhesive. Such a leaflet could display a cutaway view of a house identifying common sources of ignition and graphically showing the path of vapors from one room to the next and from one floor to next. A graphical representation would allow users to make inferences regarding vapor flammability that, as our results indicate, are not being made by the majority of people even after they read the 160 label. While this type of nonprocedural information is at risk of being filtered by the user, research by Frantz and Rhoades (1990) suggests that warning information that interrupts or interferes with task accomplishment is likely to be substantially more effective than warning information that does not. Therefore, a leaflet that temporarily interrupts a user's interaction with the adhesive is likely to draw more attention than information simply added to the current label.

In closing, we note that determining the merits of these recommendations requires empirical research along the lines of that described herein. While such research is likely to require skills and experience beyond that found in most companies, this study illustrates that field research is, in fact, technically feasible given the assistance of human factors professionals. To increase the economic feasibility of warning label evaluations, manufacturers of the same type of product (e.g., flammable adhesives) should consider working together, through their trade associations, to conduct research on issues common to their products.

\section{ACKNOWLEDGMENTS}

The authors extend thanks to Timothy $P$. Rhoades for his insight and suggestions during the various stages of this research. The first author gratefully acknowledges the U.S. Air Force Office of Scientific Research whose graduate fellowship funding provided partial support for this research effort. Requests for reprints should be sent to J. Paul Frantz, P.O. Box 7995, Ann Arbor, MI, $48107,(313) 662-6822$.

\section{REFERENCES}

Canada Gazette, Part I. (1989). Hazardous Products Act Amendant (Part II) and Hazardous Products (Flammable Adhesives) Regulations. August 19, 1989, 3755-3760.

Collins, B. L., Lerner, N. D. \& Pierman, B. C. (1982). Symbols for industrial safety. (NBSIR 82-2485). Washington, D.C.: National Bureau of Standards.

Easterby, R. S., \& Hakiel, S. R. (1981). Field testing of consumer safety signs: The comprehension of pictorially presented messages. Applied Ergonomics, 12(3), $143-152$.

Federal Register. (1977a). Extremely flammable contact adhesives, 42(134), July, 13, 1977, 35983-35990.

Journal of Safety Research 
Federal Register. (1977b). Extremely flammable contact adhesives: Establishment as banned hazardous product; labeling, 42(243), December, 19, 1977 , $63730-63741$.

Frantz, J. P., \& Rhoades. T. P. (1990). The effect of warning location and task interruption on attention to and compliance with product warnings. (Unpublished research report). Ann Arbor, MI: University of Michigan.

Friedmann, K. (1988). The effect of adding symbols to written warning labels on user behavior and recall. Human Factors, 30(4), 507-515.

Gallup Canada. (1989). Consumer survey on the labelling and packaging of hazardous chemical products, Volume I: Detailed findings. June 7, 1989.

Laux, L., Mayer, D. L., \& Thompson, N. B. (1989). Usefulness of symbols and pictorials to communicate hazard information. In Proceedings of Interface '89 The Sixth Symposium on Human Factors and Industrial
Design in Consumer Products (pp. 79-83). Santa Monica, CA: Human Factors Society.

Lehto, M. R., \& Miller, J. M. (1986). Warnings: Volume I: Fundamentals, design, and evaluation methodologies. Ann Arbor, MI: Fuller Technical Publications.

Nelson, T. M. (1976, October). Hazard analysis on contact adhesive fires. Washington, D.C: U.S. Consumer Product Safety Commission Draft Report.

Tierney, W. J., \& King, L. E. (1970). Traffic signing symbols versus words. The Sixth World Highway Conference of the International Road Federation (pp. 1-40). Montreal, Canada.

Tversky, A., \& Kahneman, D. (1974). Judgment under uncertainty: heuristics and biases. Science, 185 , 1124-1131.

Wright, P., Creighton, P., \& Threlsall, S. M. (1982). Some factors determining when instructions will be read. Ergonomics, 25 (3), 225-237. 